\title{
Las pasiones de Juana la Loca en el cine español: desde la Historia y el Teatro a las adaptaciones, readaptaciones y remakes compuestos
}

\section{The passions of Joanna the Mad in Spanish cinema: from history and theatre to adaptations, re-adaptations and mixed remakes}

\author{
Miguel DÁvila Vargas-MaCHUCA \\ Universidad Internacional de Andalucía \\ mdavilavm@gmail.com \\ ORCID ID: 0000-0001-7442-4509
}

\begin{abstract}
Resumen: Juana I de Castilla, por desgracia también conocida como Juana la Loca, es una importante figura histórica cuya convulsa biografía generó fascinación e interés sobre todo desde el Romanticismo, cuando se configuró una imagen idealizada de ella en diversas manifestaciones artísticas. El drama teatral La locura de amor (Manuel Tamayo y Baus, 1855) es la base argumental de la mayoría de películas sobre Juana en el cine español. El análisis de estas producciones permite identificar diferentes trasvases de la Literatura al Cine y los condicionantes ideológicos, políticos o sociológicos de cada momento de producción. Historia, Literatura y Cine pueden combinarse para extraer, a partir de la figura de Juana, un reflejo de los cambios sociales de España a lo largo de más de un siglo.
\end{abstract}

Palabras clave: Cine, Literatura, Teatro, Historia, Juana I de Castilla, Manuel Tamayo y Baus, adaptación cinematográfica, remake.

\begin{abstract}
Joanna I of Castile, unfortunately also known as Joanna the Mad, is an important historical figure, whose tumultuous life caused fascination and interest from the Romantic era onwards, when an idealized image of her was shaped by diverse artistic works. The drama play La locura de amor (The Madness of Love, Manuel Tamayo y Baus, 1855) is the basis for the plot of most films about Joanna in Spanish cinema. An analysis of these productions allows us to identify different transfers from literature to cinema and the ideological, political, or sociological determining factors at the time of each production. History, literature and cinema can be combined to extract from the figure of Joanna a reflection of social change in Spain throughout more than a century.
\end{abstract}

Key Words: Cinema, Literature, Theatre, History, Joanna I of Castile, Manuel Tamayo y Baus, film adaptation, remake. 


\section{INTRODUCCIÓN}

Las conexiones entre Literatura y Cine son tan variadas como diversos sus resultados. Podemos encontrar adaptaciones de textos literarios a la gran pantalla, más o menos libres respecto a las obras originales, que se basan en un texto concreto, en parte de él o en una combinación de varios. También hay que contemplar, ante la dificultad de adaptar con total proximidad a la gran pantalla un texto literario ${ }^{1}$, la posibilidad de reescrituras, de remakes de anteriores adaptaciones o de sucesivas readaptaciones. Por otra parte, no se pueden olvidar los guiones originales a partir de los cuales se pueden desarrollar tramas cinematográficas y que, si bien no son en su concepción textos estrictamente literarios, pueden acabar generando una edición en su propia forma o como readaptación hacia ediciones más puramente narrativas.

Volviendo a las conexiones entre Literatura y Cine, si el texto literario susceptible de ser adaptado a la gran pantalla conlleva cierta recreación del pasado, la Historia se combina con el análisis de la propia adaptación. En ese caso, el interés del estudio se multiplica y diversifica, dando lugar no solo a conclusiones sobre el trasvase de la Literatura al Cine, o a los tradicionales componentes artísticos o industriales del medio audiovisual, sino también a identificar puntos de vista ideológicos o sociológicos en torno al conocimiento histórico. La perspectiva histórica diacrónica se sitúa entonces en el centro del análisis y demuestra que no solo es importante conocer la evolución de una cultura o sociedad, sino también la influencia que tiene en su desarrollo el recurso consciente o inconsciente al pasado.

El Cine es una valiosa herramienta de escritura histórica, un instrumento que puede generar una determinada visión del pasado o hacer llegar al público determinados valores o ideales. Las películas que recrean el pasado son, en efecto, retratos interesados de tiempos pretéritos, pero también recipientes de ideas proyectadas desde el mismo presente en el que se realizan. En este sentido, el trabajo desde hace décadas de diversos autores como Marc Ferro, Pierre Sorlin o Robert Rosenstone consiguió al

1 Hablar de fidelidad es algo bastante relativo que debe atender sobre todo a la intencionalidad de cada autor, literario o cinematográfico, respecto a su obra. No es necesario ni obligatorio adaptar fielmente, porque cada trasvase de la Literatura al Cine tiene sus propios condicionantes y objetivos, sin necesidad de plegarse ciegamente al punto de partida, y son muchos los ejemplos de películas demasiado cercanas al texto escrito que no funcionan bien como documento audiovisual. Al respecto de las relaciones entre Literatura y Cine (y, en concreto, de las adaptaciones cinematográficas) recomiendo el artículo de Rafael Malpartida Tirado «La recepción y el canon de la literatura y el cine: sugestiones y replanteamientos» (2018: 17-53). 
fin dotar al Cine de la categoría de documento histórico. Estos y otros investigadores confluyen en la teoría de la doble dimensión histórica del Cine, según la cual las películas que recrean algún momento pasado lo hacen incluyendo una perspectiva del presente, por lo que duplican su valor como documentos históricos. De hecho, esta doble historicidad no tiene por qué ser exclusiva de las películas de recreación histórica, sino que toda película, independientemente de su género y ambientación, lleva implícitos un mensaje y un retrato del presente de su producción que, transcurrido cierto tiempo, la convierten en un testimonio histórico de la sociedad o la ideología de su época:

Aunque en el espectador común puede encontrarse todavía un margen aceptable de credulidad, todos los estudiosos están ya de acuerdo en que el cine histórico ha mostrado siempre el pasado desde la perspectiva del presente. Por rigurosa que sea la recreación de escenarios y vestuario, los personajes hablan y actúan como lo harían en la época en que se produjo la película, es decir, siguiendo los usos y costumbres del momento y, si es necesario, emitiendo un mensaje favorable a las corrientes de pensamiento dominantes, de forma sutil en sistemas políticos más o menos democráticos y más ruda en las dictaduras (España, 2013: 45).

Centrando el punto de vista en Juana I de Castilla, no cabe duda de que se trata de una importante figura de la Historia de España que ha generado gran interés a lo largo del tiempo, como corresponde a un personaje rodeado de muchos enigmas, en especial el de su supuesta locura, el aspecto responsable del sobrenombre por el que ha pasado a la posteridad. La fascinación por ella ha inspirado revisiones desde diferentes disciplinas humanísticas y artísticas, especialmente desde la época del Romanticismo. Pinturas, novelas, biografías, poemas, temas musicales, óperas u obras teatrales se han acercado a su persona, y el Séptimo Arte no es una excepción, sobre todo en el cine español ${ }^{2}$.

La presencia de Juana la Loca en la gran pantalla es un buen ejemplo para poder identificar distintas formas de relacionar Literatura y Cine mediante adaptaciones, reescrituras o remakes. Al mismo tiempo, teniendo en cuenta el mencionado doble potencial histórico de las películas que muestran hechos y personajes del pasado, el análisis de sus representaciones desde la época muda hasta nuestros días permite entender el trasfondo de sus procesos de producción y la perspectiva de presente que subyace en cada una de estas obras audiovisuales. Así mismo, el tratamiento en las obras literarias y cinematográficas de una

\footnotetext{
2 Santiago Juan-Navarro (2005: 213-214, nota 1) propone una amplia lista de estas representaciones artísticas de Juana I de Castilla.
} 
figura femenina tan importante añade aspectos muy interesantes para comprender la diversidad de tratamiento de las mujeres a lo largo del tiempo, desde el Romanticismo, pasando por el nacional-catolicismo o la comedia ligera, hasta una sólida perspectiva de género en el nuevo milenio.

\section{El personaje histórico: Juana I de Castilla}

Juana I de Castilla es un personaje capital de la Historia de España, inserto en una época crucial tanto en términos de política interior como internacional, y protagonista de forma directa o indirecta en hechos muy destacados en los momentos iniciales de la Edad Moderna. A pesar de ello, existe gran controversia en torno a su figura, que derivó en un desprecio hacia ella desde su presente vital y que confluye en los supuestos trastornos mentales que derivaron en su desdichado sobrenombre.

Juana, nacida en Toledo en 1479, fue la tercera descendiente y segunda hija de Isabel I de Castilla y Fernando II de Aragón, los Reyes Católicos. Sus padres concertarían su matrimonio de conveniencia con el hijo del emperador del Sacro Imperio Romano Germánico Maximiliano de Austria y de María de Borgoña como parte de sus maniobras diplomáticas para hacer frente al poderío de la monarquía francesa. El enlace tuvo lugar en Flandes en 1496, momento en el que la joven Juana, entonces con 16 años de edad, se convertía en la esposa del archiduque Felipe de Habsburgo, apodado el Hermoso. Juntos tendrían una ilustre descendencia que continuaría el plan diplomático de los Reyes Católicos para ocupar importantes tronos y emparentarse con destacadas dinastías europeas. Su primogénita, Leonor (1498-1558), llegaría a ser reina consorte de Portugal y después de Francia. El segundo descendiente, Carlos (1500-1558), sería el más destacado de todos, convirtiéndose en el primer soberano que reunía en su persona las coronas de Castilla y Aragón con el nombre de Carlos I, además de suceder a su abuelo Maximiliano en el trono imperial como Carlos V. La tercera hija, Isabel (1501-1526), llegaría a ser reina de la Unión de Kalmar (Dinamarca, Suecia y Noruega), mientras que el cuarto vástago, Fernando (15031564), sucedería como emperador a su hermano Carlos, además de ser rey de Bohemia y Hungría. La quinta hija, María (1505-1558), fue reina de Hungría y Bohemia (justo antes que su hermano Fernando) y después gobernadora de los Países Bajos Españoles. Por último, Catalina (15071578), hija póstuma de Felipe y sexta descendiente del matrimonio, llegaría a reinar en Portugal.

La vida no fue nada sosegada para Juana, ya que en torno a ella se fueron sucediendo todo tipo de circunstancias y hechos negativos que 
condicionaron su vida familiar $\mathrm{y}$, sobre todo, su actividad política. Partiendo de la esfera privada, a caballo entre la leyenda y la realidad hay que mencionar ciertas infidelidades por parte de Felipe, que podrían haber exacerbado el temperamento apasionado de Juana para dar lugar a comportamientos irracionales que se conocerían tanto en su corte de Flandes como en Castilla. En cuanto al componente público de Juana, las maniobras diplomáticas de sus padres y de su propio marido para controlar el poder derivado de sus títulos generarían todo tipo de desavenencias políticas que llegaron hasta el plano personal y que sin duda pusieron a prueba los nervios y la entereza de esta insigne mujer. De hecho, Juana se convirtió en la heredera de una de las mayores concentraciones de dominios territoriales hasta el momento (incluyendo las recientes y vastas conquistas en América) tras la muerte de algunos familiares, especialmente el príncipe Miguel, nacido en 1498 como hijo de su hermana Isabel (quien murió en el parto) y del rey Manuel de Portugal:

Miguel $[\ldots]$ se convertía en único y exclusivo heredero de los tres reinos peninsulares y abría la posibilidad de la unión de Portugal, Castilla y Aragón [...]. Al morir en 1500 el príncipe Miguel y quedar sin heredero varón, según las leyes y usos de Castilla era Juana la que pasaba a ser heredera y, en su día, reina propietaria y legataria del reino; no tan claro, en Aragón (Bernal, 2007: 44, 57).

Para refrendar esta condición, Juana y Felipe debieron abandonar Flandes en cuanto les fue posible, siendo jurados como herederos por las Cortes de Castilla en mayo de 1502. Felipe salió de tierras castellanas a finales del mismo año, pero Juana quedaría allí por designio de sus progenitores hasta la primavera de 1504, dando lugar a un segmento poco conocido de su desdichada vida:

Los meses de estancia de la princesa Juana en Castilla y, finalmente, su salida a Flandes es un capítulo de la historia española que por sí solo podría nutrir los relatos más inverosímiles, por su truculencia. El feroz enfrentamiento de la hija con su madre, aquélla queriendo partir a toda costa para reunirse con su marido y la reina Isabel impidiéndoselo y tratando de retenerla, aun por la fuerza, en la Mota hasta el punto de quejarse la hija a su progenitora de querer descasarla (Bernal, 2007: 62).

Teniendo en cuenta estas desavenencias en Castilla y las noticias preocupantes que les llegaban de Flandes sobre el comportamiento 
irracional de Juana ${ }^{3}$, Isabel maniobró en los últimos momentos de su vida para intentar preservar el poder de su hija, recelando del acercamiento político de Felipe hacia la monarquía francesa y tomando como excusa los trastornos irracionales de Juana, ya fueran fundados o convenientemente inventados:

La cuestión de si Felipe sería en su momento mero rey consorte, o por el contrario, rey efectivo -según la tradición europea, Aragón incluido, y del imperio donde las mujeres podían reinar pero nunca gobernar- no fue abordada ni explicitada de manera inequívoca en los años que transcurren entre 1500 y 1504, año en que fallece la reina Isabel la Católica. De ahí la complejidad de las relaciones durante esos años entre los Reyes Católicos y el matrimonio de Juana y Felipe, una complejidad debida, más que a los signos manifestados por la infanta castellana de enajenación, a la cuestión política de fondo que estaba en juego (Bernal, 2007: 57).

Isabel dejó instrucciones en su testamento especificando que, en caso de que Juana no estuviera en condiciones de administrar sus posesiones, sería su padre, Fernando de Aragón, quien ejercería la regencia hasta que tuviera una edad suficiente para el gobierno Carlos, el segundo hijo y primer varón de Juana y Felipe, heredero natural de las coronas de Castilla, Aragón y el Sacro Imperio Romano Germánico.

La muerte de Isabel en 1504 precipitó los acontecimientos políticos en torno a Juana, ya que en ese momento ella y Felipe se convertían en reyes de Castilla. Pero afloró entonces la disputa por el poder nominal de la recién proclamada soberana castellana, que evidentemente ansiaba Felipe como consorte de la legítima heredera, pero que recaía en Fernando según el testamento de Isabel. La situación derivó en un enfrentamiento entre los partidarios de Fernando de Aragón y los de Felipe, en su caso secundado por gran parte de la nobleza castellana, que quería resarcirse de la pérdida de poder sufrida bajo el reinado de Isabel. Las maniobras e intrigas palaciegas coincidían, por desgracia para Juana, en la supuesta incapacidad planteada en el testamento de su madre, que era esgrimido por Fernando para hacer efectiva la última voluntad de su mujer. Por su parte, Felipe tomaría esta condición de Juana como excusa para ejercer él solo el poder en nombre de su esposa. La llegada del matrimonio desde Flandes a Castilla en 1506 supuso la definitiva ratificación de las

\footnotetext{
${ }^{3}$ Martín de Móxica, un hombre de confianza de Felipe, recibió de este el encargo en 1504 (a la vuelta de su esposa a Flandes) de «que llevara un diario referente a la conducta de Juana, y lo envió, para su justificación, a los padres de ella» (Pfandl, 1969: 59). Se trata por tanto de un documento muy interesado y de difícil veracidad, habida cuenta de las maniobras políticas de Felipe para denostar a su mujer e intentar hacerse con el trono de Castilla de forma exclusiva.
} 
aspiraciones de Felipe, quien consiguió en dos encuentros con Fernando, «la concordia de Salamanca y el convenio de Villafáfila» (Bernal, 2007: 68), que el monarca aragonés renunciara a su regencia y abandonara Castilla, dejándole vía libre para gobernar de facto y no como simple consorte. De hecho, Felipe comenzó a reinar en solitario, desoyendo el acuerdo de las Cortes de Castilla, que «juran en julio de 1506 a Juana como reina propietaria y única con capacidad para transmitir la herencia del reino, a Felipe como rey propietario y a Carlos, hijo primogénito de ambos, como heredero» (Bernal, 2007: 69).

Pero el reinado efectivo de Felipe I de Castilla fue efímero, apenas un par de meses, ya que moría en Burgos en septiembre del mismo año, a los 28 años de edad, después de una dolencia repentina. Nuevo y durísimo varapalo para Juana, que en el mismo año había sido apartada del poder y había perdido a su amado esposo. Mientras el cardenal Cisneros ejercía la regencia a la espera de la vuelta de Fernando de Aragón desde tierras italianas, Juana quiso cumplir la voluntad de Felipe de ser enterrado en Granada, por lo que se puso en marcha junto al féretro de su esposo en una peculiar comitiva nocturna, un hecho que acrecentó las habladurías populares sobre su enajenación mental. La comitiva tuvo que detenerse en Torquemada, donde Juana dio a luz a Catalina, hija póstuma de Felipe, en enero de 1507.

De vuelta en Castilla, Fernando se entrevistó con Juana en agosto de 1507, acordando ambos cumplir con lo dispuesto en el testamento de Isabel, por lo que el soberano aragonés asumía la regencia hasta la mayoría de edad de Carlos. Juana, que siguió apareciendo en la documentación oficial como reina propietaria de las coronas de Castilla y Aragón, y cuya supuesta incapacidad no había llegado a ser reconocida por las Cortes de Castilla, no llegaría a ejercer de forma efectiva su poder, sobre todo desde que en 1509 recibiera un nuevo y definitivo revés político (y personal): la decisión de su padre de encerrarla en el castillo de Tordesillas a perpetuidad. Se eliminaba así cualquier posible maniobra que se valiera de su persona para desestabilizar esa herencia conjunta de los Reyes Católicos que desembocaba en Carlos I.

Después de la muerte de Fernando II de Aragón y de una nueva regencia del cardenal Cisneros, Carlos se convertía en 1517 en el primer rey que reunía las coronas de Castilla y Aragón por herencia de sus abuelos maternos, además de sumar los dominios de sus abuelos paternos, incluyendo el trono imperial. Por entonces Juana seguía manteniendo su condición nominal de reina, pero permaneció encerrada en Tordesillas también por decisión de su propio hijo, continuando el deseo de evitar posibles simpatías hacia ella. De hecho, la llegada de un monarca extranjero como Carlos no fue aceptada de buen grado, y uno de los mayores ejemplos de este descontento fue la Guerra de las Comunidades 
(1520-1522), precisamente la última vez que Juana tuvo alguna relevancia pública, ya que los comuneros castellanos sublevados la reconocieron como soberana, aunque ella no quiso finalmente ejercer su poder. Después de una reclusión de 46 largos años, Juana moría en Tordesillas en 1555, con 75 años de edad, como una mujer que había sido despreciada y despojada de su poder por motivos políticos.

La locura que se le presupone, sin pruebas fehacientes que la corroboren, debe mucho a la construcción romántica de su figura, cuando se identificó de forma idealizada su trastorno con unos celos exacerbados. Pero esas perspectivas han cambiado con el tiempo y parece muy aceptada la opinión de que Juana «estaba enferma, pero no loca, era esquizofrénica» (López López, 2004: 128). El primer investigador que habló en este sentido fue el historiador e hispanista alemán Ludwig Pfandl, autor de la influyente biografía Johanna die Wahnsinnige. Ihr Leben, ihre Zeit, ihre Schuld (1930), traducida al español en 1932. Según Pfandl,

en ella no se observa psicosis alguna endógena ni exógena; no era melancólica ni padecía locura depresiva de índole maníaca; no padecía cretinismo ni demencia paralítica ni epilepsia ni idiotez. Pero mostraba en forma inequívoca todos los caracteres de la demencia precoz o esquizofrenia, que es un trastorno en el proceso de asociación (1969: 85).

Más allá de elucubraciones normalmente negativas para la memoria de Juana ${ }^{4}$, hay que pensar que sus trastornos pudieron ser la consecuencia de presiones políticas, intrigas palaciegas y desprecios personales que sufrió durante largo tiempo. Aunque no tengamos datos directos, estos agravios y desencantos pudieron ponerla al límite y derivar en el temperamento inusual y atormentado que ha pasado a la posteridad como locura. No hay más que pensar en cómo fue utilizada y maltratada antes de ser considerada incapaz por sus seres queridos (su madre, su padre y su esposo), y que su posterior encierro (decretado por su padre y confirmado por su hijo Carlos) y el consiguiente aislamiento podrían haber tenido graves consecuencias, como ya apuntaba Pfandl:

lo que produjo malos efectos también en el caso de Juana fue la severa reclusión y el trato irracional inherente a ella. El aislamiento y la asistencia

\footnotetext{
${ }^{4}$ Este texto no pretende entrar en consideraciones patológicas, pero el interés en el estado mental de Juana continúa en la actualidad, a pesar de chocar con siglos de distancia, pocos datos directos fiables y manipulaciones. Ejemplo de ello es el artículo del psiquiatra Luis Mínguez Martín «Psicobiografía de Doña Juana I de Castilla y Aragón» (2004).
} 
Las pasiones de Juana la Loca en el cine español

inadecuada de los esquizofrénicos, dice la moderna psiquiatría, empeoran su estado rápida y profundamente (1969: 88).

\section{Teatro: el SUSTRATO DE las adAPTACiOnes Cinematográficas SOBRE JUANA}

Después de tres siglos de olvido ${ }^{5}$, en la España del Romanticismo se suscitó el interés en la enigmática y fascinante personalidad de Juana I de Castilla:

El movimiento romántico español, que sobrevivía en sus aspectos más casticistas y reaccionarios dentro del teatro, la historiografía y la pintura finiseculares, vio en la reina Juana no sólo la encarnación de la pasión desatada, la enajenación provocada por los celos y la necrofilia (motivos todos ellos genuinamente románticos), sino también la personificación de toda una leyenda nacionalista: la locura de Juana como consecuencia de las intrigas orquestadas por los cortesanos flamencos durante el período de consolidación del imperio español (Juan-Navarro, 2005: 204).

Los pocos datos disponibles sobre la infortunada reina permitieron que el interés derivara en la idealización de su supuesta locura, generando un entramado ficticio de poderoso influjo posterior en las interpretaciones artísticas sobre ella.

Desde el campo literario, el autor que creó la obra más influyente sobre Juana fue el dramaturgo madrileño Manuel Tamayo y Baus (18291898). Miembro de una conocida familia vinculada al Teatro, este importante representante de las letras españolas del siglo XIX llegaría a ser miembro de la Real Academia Española en 1858, así como director de la Biblioteca Nacional y secretario perpetuo de la Real Academia Española en 1870. De una producción con más de cincuenta obras, entre las que destacan comedias y dramas históricos, la crítica considera que su culmen es Un drama nuevo (1867), «una pieza excelente [...] que obtuvo una acogida extraordinaria que se prolongó durante medio siglo, alcanzando en vida del autor al menos siete ediciones» (Rubio Jiménez, 2004: 678); ambientada en la Inglaterra isabelina, adoptaba el recurso del Teatro dentro del Teatro para acercarse a la figura de Shakespeare.

Tamayo y Baus recuperó la figura de Juana I de Castilla en La locura de amor (1855), un drama histórico en prosa que bascula entre el Romanticismo y el Realismo para dar lugar a unos diálogos bastante naturales, y que tuvo gran éxito en su momento ${ }^{6}$. Su trasfondo histórico

${ }^{5}$ «Almost entirely forgotten as an historical figure three hundred years after her death» (Juan-Navarro, 2008: 210). 
es figurado y novelesco, pero no pretende alejarse demasiado del conocimiento disponible sobre Juana y quienes la rodearon. El argumento, tal como anuncia su título, se centra en el amor exagerado de Juana por su esposo, así como en los celos fundados por las infidelidades de Felipe. El autor hace justicia a Juana despojándola de la supuesta demencia para humanizarla y dotarla de una dignidad férrea frente a toda clase de intrigas palaciegas.

La acción de La locura de amor tiene lugar en una cronología muy reducida en el año 1506 y se desarrolla en ese presente de forma lineal, sin saltos temporales. Toda la obra se localiza en Castilla, concretamente el primer acto en un palacio de la localidad vallisoletana de Tudela de Duero, el segundo en un mesón cercano a Tudela, y los tres restantes en el Palacio de los Condestables de Castilla en Burgos. A lo largo de esos cinco actos se va enredando y desenredando un círculo amoroso que parte del personaje principal de Juana, enamorada de su marido Felipe, quien a su vez caerá rendido ante la enigmática Aldara, una muchacha que se hace pasar por sobrina del mesonero Garcipérez; esta, por su parte, quiere ser correspondida por el caballero castellano don Álvar, quien por otro lado siente una admiración rayana en el amor por la reina. Para complicar un poco más el círculo amoroso, Juana se servirá de don Álvar para darle celos a su marido y que este vuelva a amarla, mientras que Aldara hará lo propio con el rey para intentar atraerse el amor de don Álvar. Tanto la persona de Juana como los designios del Reino de Castilla se verán asistidos no solo por don Álvar, sino también por otros personajes secundarios como su doncella doña Elvira, el almirante de Castilla, el médico Marliano y el paje Hernán. Pero como trasfondo de la acción, Felipe intentará aprovechar la supuesta locura de Juana para apartarla de sí y poder dar rienda suelta a su amor por Aldara, mientras que los nobles don Juan Manuel, el marqués de Villena y don Filiberto de Vere le secundan en sus tretas con ansias propias de alcanzar mayor poder.

Este drama de Tamayo y Baus es la base literaria para la mayoría de visiones cinematográficas centradas en la figura de Juana. Si se tienen en cuenta las películas que la toman como personaje protagonista, casi todas tienen alguna relación con La locura de amor, bien de forma directa o a partir de otras películas. Los ejemplos disponibles provienen del cine español $^{7}$ y parten desde la etapa muda con dos producciones (en 1909 y

\footnotetext{
${ }^{6}$ «La obra gozó de un gran éxito en la época, siendo traducida rápidamente al portugués, francés, inglés, italiano y alemán» (López López, 2004: 120).

${ }^{7}$ La única excepción es la italiana Giovanna la Pazza, dirigida por Mario Caserini en 1910, de la cual solo hay escuetas referencias en Internet, tanto en Internet Movie
} 
$1926)^{8}$, otras dos en el siglo XX ya en etapa sonora (en 1948 y 1983) y llegando hasta el nuevo milenio con las dos últimas hasta la fecha actual (en 2001 y 2016).

\section{LA PRIMERA ADAPTACIÓN CINEMATOGRÁFICA}

Albert Marro y Ricard de Baños dirigieron la primera adaptación cinematográfica de la obra de Tamayo y Baus en $1909^{9}$, una producción de título homónimo realizada en el seno de la empresa Hispano Films. La acción se encuentra dividida en escenas estáticas sin movimiento de cámara, al estilo de las pinturas historicistas y recogiendo la moda de recreaciones históricas y adaptaciones de clásicos literarios iniciada por la compañía francesa Film d'Art en 1908, de enorme influencia a nivel mundial, y concretamente en España con títulos afines como el que Marro y Baños habían realizado en 1908 adaptando el Don Juan Tenorio de Zorrilla. El contenido metraje de Locura de amor se traduce en una adaptación ligera y escueta, y los fragmentos conservados permiten identificar que la acción se desarrolla en tierras castellanas, en un corto segmento temporal presente y lineal, en el año 1506.

En cuanto al sencillo argumento, Juana, encarnada por Amelia de la Mata, descubre la infidelidad del rey mediante una carta que insta al soberano a encontrarse con una misteriosa mujer en un humilladero mientras está de caza. Más adelante otra carta anónima lleva a la reina a llamar a sus cortesanas para desenmascarar a una de ellas a partir de su escritura, aunque se habla de que la mujer en cuestión posee una «melena rubia», mientras que la chica a la que castiga cortándole su larga cabellera es morena. Después el Consejo de Castilla se reunirá para declarar la incapacidad de la reina.

La película finaliza con la escena de la comitiva fúnebre de Felipe, presentando a una Juana apesadumbrada junto al féretro de su difunto marido. Esta puesta en escena reproduce el cuadro de Francisco Pradilla (1848-1921) Doña Juana la Loca con el féretro de Felipe el Hermoso (1877),

Database (http://www.imdb.com/title/tt0216773/) como en Wikipedia (http://it.wikipedia.org/wiki/Giovanna la pazza \%28film 1910\%29).

${ }^{8}$ Algunos autores, como Santiago Juan-Navarro (2005: 206; 2008: 212) o Vicente Sánchez-Biosca (2012: 508, nota 25), hacen referencia a Locura de amor, dirigida por Miguel Villar Toldán en 1926, pero no pasan de la simple mención, sin más datos, por lo que no será tratada en este texto.

${ }^{9}$ Dentro de las muchas informaciones poco concretas de los inicios del cine español (y del cine mundial en general), la fecha de estreno de la película fluctúa entre la mayormente aceptada de 1909, según autores como José María Caparrós Lera (2007: 36) o Julio Pérez Perucha (2000: 33), mientras que Luis Gasca (1998: 300) la sitúa en 1913. 
un tableau-vivant conservado en el Museo del Prado. De hecho, esta imagen extraída directamente de la pintura historicista se repetirá en posteriores adaptaciones cinematográficas de la obra de Tamayo y Baus.

\section{LA ADAPTACIÓN CANÓNICA}

En 1948 se estrenaba la primera adaptación cinematográfica sonora de la obra de Tamayo, también con el título de Locura de amor, y con un insigne y prolífico director al frente, el madrileño Juan de Orduña (19001974). Orduña, cuya carrera cuenta con casi medio centenar de títulos como director, pasó por diversos géneros, si bien es conocido sobre todo por sus obras de trasfondo histórico o literario. Algunas de ellas tuvieron gran éxito de público y han pasado a la posteridad como hitos destacados del cine español, siendo algunos ejemplos ¡A mí la legión! (1942), La Lola se va a los puertos (1947), Agustina de Aragón (1950), Alba de América (1951), Cañas y barro (1954), Zalacaín el aventurero (1955), El último cuplé (1957), La Tirana (1958), Teresa de Jesús (1961) o Nobleza baturra (1965).

Durante la etapa de la autarquía o primer franquismo, entre el fin de la Guerra Civil y los inicios de la década de 1950, el bando sublevado y a la postre vencedor entendió la necesidad de crear una retórica propagandística que basaba «gran parte de su efectividad en una drástica reescritura de la Historia, considerada como el necesario cemento ideológico para establecer la legitimidad del nuevo régimen» (Torreiro, 1999: 54). En esta coyuntura de cruzada ideológica, el cine español se convirtió en un valioso instrumento del franquismo, que vio la posibilidad de utilizar el género histórico como un medio «especialmente importante de cara a la "formación del espíritu nacional"» (Tusell, 1999: 269). Por ello, los títulos mencionados de la filmografía de Orduña, que retrataban episodios y personajes de la Historia Moderna y Contemporánea de España, entroncaron perfectamente con esta instrumentalización ideológica y propagandística. Sus cintas de recreación histórica (incluida Locura de amor), al igual que las de otros directores, respondían a

la voluntad de revisar la historia de España en un momento de consolidación del nuevo estado. La propuesta básica era demostrar una continuidad histórica a través de dos conceptos que se mantuvieron inalterables durante los siglos. Por un lado, una idea intemporal de lo español, normalmente definida por oposición a amenazas exteriores, pero también al enemigo interior y, en cualquier caso, permanente desde los inicios de la invasión musulmana hasta el presente. Por otro lado, como se desprende de lo anterior, la incuestionable identidad nacional construida bajo la guía de la religión católica, capaz de reunir en su seno tanto las distintas capas sociales como las diversas regiones y culturas que configuraban la sociedad española, además de dar respuesta y consuelo a las desgracias o a los devaneos de las pasiones humanas (Benet, 2012: 221). 
Además, al recurrir en algunas de sus producciones a ilustres figuras femeninas de la Historia de España, Orduña respondía a una de las líneas propagandísticas del cine del momento, ya que la «figura de la heroína histórica representó uno de los estereotipos femeninos más importantes y llamativos que se dieron en la escena cinematográfica bajo el franquismo» (Guillamón Carrasco, 2015: 115). Esta presencia de personajes protagonistas femeninos es uno de los rasgos más reconocibles del cine histórico de los inicios del franquismo:

la constitución de una insólita galería de mujeres ilustres y heroicas (reinas, heroínas, santas, madres, etc.) como inmediata referencia a la madre (patria) y a su responsabilidad como defensoras de la familia y el hogar en peligro, siempre por la vía de la abnegación y la renuncia, tanto del amor real como de un amor sublimado o sobrenatural (Monterde, 2000: 236).

En el campo de las relaciones entre Literatura y Cine, tampoco hay que olvidar que Locura de amor es parte de otra de las corrientes preferidas del cine de la autarquía:

en este contexto cinematográfico destacaba una corriente de adaptación literaria, en una constante recurrencia a obras teatrales y novelas de gran conocimiento popular, donde se entremezclan el melodrama y el folletín protagonizados por una heroína que actúa como víctima y lucha contra lo imposible. Temática y estructuralmente esta vertiente apunta al argumento y estilo de Locura de amor (López López, 2004: 120).

El proyecto de Locura de amor venía de largo, con diversos retrasos e inconvenientes desde 1941, incluidos descartes de directores (Benito Perojo, Manuel Augusto García Viñolas, José López Rubio, Rafael Gil), intérpretes que fueron abandonando el elenco (Armando Calvo, Amparo Rivelles, Mary Carrillo, Alfredo Mayo, José Sánchez) (Seguin, 1997: 230232), guiones que se reescribieron, derechos que cambiaron de manos... En 1944 la productora valenciana CIFESA se hizo con los derechos de la obra de Tamayo y Baus, y en el guion definitivo colaboró Manuel Tamayo, nieto del propio dramaturgo. Finalmente se eligió como director a Juan de Orduña, quien ya había adaptado poco tiempo antes otra obra de Tamayo y Baus, Un drama nuevo (1946). En el reparto, tras diversos descartes a lo largo de los años, se contaría definitivamente con estrellas como Fernando Rey en el papel de Felipe, Jorge Mistral en el de don Álvar y Sara Montiel en el de Aldara, mientras que para encarnar a Juana se escogió a la principiante Aurora Bautista. El rodaje tuvo lugar entre octubre de 1947 y febrero de 1948, y el estreno en Madrid el 8 de 
octubre del mismo año, convirtiéndose en uno de los grandes éxitos de público del momento ${ }^{10}$, y cosechando multitud de premios ${ }^{11}$.

Locura de amor es sin duda la adaptación cinematográfica más próxima al drama de 1855, marcando un canon que influye en la mayoría de películas posteriores sobre Juana I de Castilla. En su acción excede la escueta cronología de la obra de Tamayo, iniciándose en el presente de 1517, cuando el joven rey Carlos I llega a Castilla y visita a su madre en Tordesillas. Una reacción desaforada de Juana provoca el desconcierto en Carlos, pero el caballero don Álvar de Estúniga se dispone a relatarle los hechos que provocaron ese episodio demencial de su madre. La narración se plantea desde entonces en amplios flashbacks que llenan la mayor parte del metraje, solo interrumpidos por planos fugaces en 1517 en los que don Álvar, bien sea en persona o con su simple voz fuera de plano ${ }^{12}$, continúa relatando los hechos al rey Carlos. Estas prolongadas analepsis recrean los hechos acaecidos desde la recepción de la noticia de la muerte de Isabel la Católica en la corte de Flandes a finales de 1504, pasando por la llegada de Juana y Felipe a Castilla, hasta la muerte de este en septiembre de 1506. Por lo tanto, el núcleo del argumento recrea algo menos de dos años en la vida de una mujer que llegó hasta los setenta y cinco, una maniobra que se antoja necesaria para tomar muy en cuenta los hechos históricos del contexto. No en vano, estos dos años marcaron de forma crucial la vida privada de Juana, pero también la política, y una figura tan importante debía ser tratada con mucho respeto, así como los personajes históricos que la rodearon. Este planteamiento seguía las directrices en cuestiones de propaganda del estado franquista, que consideraba como fundamental para alcanzar la categoría de "Película de interés nacional" que una producción «contenga muestras inequívocas de exaltación de valores raciales o en enseñanzas de nuestros principios morales y políticos» ${ }^{13}$. En lo referente a las localizaciones de la película,

\footnotetext{
${ }^{10}$ «Locura de amor fue la película española más vista durante la década de los cuarenta, manteniéndose tras su estreno en Madrid 136 días en cartel» (Benet, 2012: 223).

11 Primer Certamen Cinematográfico Hispano-Americano (1948): Mejor película española, Mejor dirección (Juan de Orduña), Mejor interpretación femenina (Aurora Bautista), Mejor interpretación masculina secundaria (Jesús Tordesillas), Mejor ambientación musical (Juan Quintero) y Mejores decorados (Sigfrido Burman); Círculo de Escritores Cinematográficos (1948): Mejor película y Mejor actriz protagonista (Aurora Bautista); Sindicato Nacional del Espectáculo (1948): Primer Premio mejor película; Triunfo (1949): Mejor actor (Jorge Mistral).

${ }^{12}$ Suelen usarse los términos «voz en off» (entendido como "fuera" del plano) o «voice over» (en el sentido de superposición a las imágenes), pero prefiero usar en este texto «voz fuera de plano».
} 
añade a las que ya aparecían en la obra de Tamayo tanto el castillo de Tordesillas en el que estaba confinada Juana como la corte de Flandes.

En cuanto a la trama, tiene mucha afinidad con el texto teatral, pero, respecto al círculo de amores no correspondidos planteado por Tamayo y Baus, en la cinta de Orduña se pierde el uso consciente de don Álvar por parte de Juana para provocar celos en Felipe. De hecho, el supuesto amor del caballero castellano por su reina se convierte en una especie de admiración hacia una gran mujer. Y, en mitad de todo este enredo amoroso, las maniobras de Felipe para demostrar la locura de Juana y así poder satisfacer su amor por la intrigante Aldara. En esta ocasión el rey demuestra desde tierras flamencas su desprecio hacia el apasionado amor que le demuestra Juana, y sus infidelidades provocarán el trastorno de Juana, que simplemente se siente abandonada por su marido. Pero Felipe no tiene más que ambiciones amorosas hacia Aldara, mientras que sus nobles acólitos (de nuevo don Juan Manuel, el marqués de Villena y don Filiberto de Vere) irán apartando a Juana del poder mediante intrigas que incluyen a Aldara, y que tienen que ver más con la propia codicia que con asuntos de estado. Mientras tanto, Juana aumentará paulatinamente su pesar, mientras que sus nervios se pondrán al límite por esas intrigas a partir de la presencia de Aldara en un mesón cercano a Tudela y su posterior llegada a palacio como dama de la propia reina. Y, por mucho que estén de su lado la dama doña Elvira, el médico Marliano, el paje Hernán o el almirante de Castilla, su consideración de loca sellará su destino incluso delante de las Cortes reunidas en Burgos. Solo la muerte podrá redimir a un arrepentido Felipe, en un pasaje también muy cercano a la obra de Tamayo y Baus.

El papel protagonista recayó en Aurora Bautista, joven y prometedora actriz teatral que con esta película realizaba su debut cinematográfico sin haber llegado a cumplir los veintitrés años de edad en el momento del estreno. Su interpretación «grandilocuente y desmesurada» (Gómez, 2006) no deja lugar a dudas sobre la proveniencia teatral tanto de la actriz como del argumento, ya que la declamación es realmente correcta, pero puede llegar a ser considerada como forzada y poco natural. En cualquier caso, su histrionismo y vena melodramática son disculpables en parte, ya que deben incidir en el amor no correspondido por su esposo y en los tremendos celos provocados por él, sentimientos exagerados por naturaleza que tienen su contrapunto en su actitud digna y noble. De hecho, entroncando con el título de la película y de la propia obra teatral de Tamayo y Baus, en algún diálogo se llega a disculpar su supuesta locura

13 Boletín Oficial del Estado, 175 (23-6-1944), pág. 4926: https://www.boe.es/datos/pdfs/BOE//1944/175/A04926-04926.pdf. 
por ser hermosa y por estar causada por el amor, mientras a su alrededor se caracteriza de manera negativa a todos los personajes que pergeñan maniobras para engañarla y dejar vía libre a Felipe en sus devaneos adúlteros, además de satisfacer la ambición de De Vere y los demás nobles afines.

La estética en general de la producción de Orduña recibe influencia de la pintura flamenca renacentista, tanto en la puesta en escena como en la propia imagen de Juana, que también se basa en los diferentes retratos que se hicieron de ella en vida. Pero existen también referencias a la pintura historicista española del siglo XIX, siendo algunos planos reproducciones directas de tableaux-vivants del romanticismo español. Por ejemplo, la escena de la muerte de Felipe muestra una puesta en escena claramente deudora de la obra de Eduardo Rosales Doña Isabel la Católica dictando su testamento (1864). De hecho, esta misma escena finaliza con el personaje de Juana llevándose un dedo a la boca para pedir silencio porque «el rey está durmiendo», una plasmación audiovisual que sin duda recibe influencia directa de la obra de Lorenzo Vallés Demencia de doña Juana de Castilla (1866).

La narración de la película termina con el final del relato de don Álvar al rey Carlos, y acto seguido muestra como último y fugaz plano una nueva recreación estática de la pintura de Pradilla Doña Juana la Loca con el féretro de Felipe el Hermoso que ya cerrara la adaptación cinematográfica de 1909. Al paralizar el plano para el rótulo del fin de la película, se cierra el círculo iniciado por el propio cuadro, que sirvió como fondo de los créditos iniciales. De este modo, la trama adopta una estructura circular «en la que el inicio nos remite al final y en la que la narrativa se abre con el desenlace» (Juan-Navarro 2005: 206). Esta estructura respondería a un entramado de círculos concéntricos, siendo el cuadro de Pradilla y su recreación estática de un hecho de 1506 un finísimo círculo exterior, dentro del cual estaría como círculo intermedio algo más grueso el inicio y final de la visita de Carlos a su madre y el relato de don Álvar (con los diferentes retornos a ese presente de 1517), mientras que el mucho mayor círculo central correspondería a los dos años de hechos en Flandes y Castilla, entre 1504 y $1506^{14}$.

\footnotetext{
${ }^{14}$ Santiago Juan-Navarro plantea también otra estructura de la película, siguiendo a Francisco Llinás: «Locura de amor adopta la estructura característica de todos los filmes históricos de Orduña, estructura que, según Francisco Llinás, responde a una doble redundancia: el film empieza por el desenlace (la locura de doña Juana) y mediante varios flashbacks se cuenta al espectador algo que ya conoce de antemano (el origen de su locura en los celos provocados por su marido, una leyenda profundamente arraigada en la tradición popular desde el siglo XIX)» (Juan-Navarro, 2005: 206).
} 
Volviendo a las cuestiones de adaptación del drama de Tamayo y Baus, no cabe duda de que esta es la película más cercana a su texto y diálogos, aunque evidentemente haya modificaciones relacionadas sobre todo con el contexto del nacional-catolicismo en el que se inserta la cinta de Orduña. La proximidad a los diálogos teatrales puede atestiguarse en diversas escenas, en las que muchas de las frases son calcadas a las de Tamayo y Baus, o bien se modifican ligeramente para intentar aportar mayor naturalidad y menor ampulosidad. Claro ejemplo es la escena en la que Juana descubre que la dama Beatriz es la moza a la que cortejaba su marido en el mesón de Garcipérez. La escena culmina con un diálogo demoledor en el que, acosada por el infeliz hallazgo y por las intrigas, la reina acepta la locura pregonada por doquier en vez de su simple desdicha amorosa.

Otra escena en la que se puede constatar la proximidad al texto de Tamayo y Baus es la sesión de las Cortes de Castilla en la Catedral de Burgos, que, si bien cambia de lugar respecto a la obra teatral (en ella estas tienen lugar en el Palacio de los Condestables), mantiene casi sin modificar las frases del discurso de Juana. Únicamente existe un cambio de entidad respecto al personaje de Filiberto de Vere, que es sobredimensionado en la cinta de Orduña para, concordando con los condicionantes ideológicos de la producción cinematográfica, potenciar la entereza de la reina castellana frente a los ardides del astuto caballero flamenco. Las malas artes de este extranjero son referidas por don Álvar al rey Carlos, identificándolo como el iniciador de todas las intrigas alrededor de Juana desde su estancia en Flandes y hasta tierras castellanas. De Vere no tenía demasiado peso en la obra de Tamayo, pero en la película sirve como exagerado antagonista que actúa de forma artera en su propio provecho, centrando sus acciones en esa consideración de Juana como incapacitada para gobernar, llegando a esgrimir la herencia genética de la locura de su abuela Isabel de Portugal, e incluso cambiando la carta que habría podido delatar la infidelidad de Felipe ante las Cortes, pero cuya desaparición pone en ridículo a Juana. En 1948 había que mantener a toda costa la dignidad de la reina, e incluso también la del rey, a pesar de haber sido caricaturizado en varias ocasiones ${ }^{15}$, puesto que cuando Felipe empieza a dar muestras de su enfermedad, De Vere también le acosa para que firme papeles importantes que paguen sus servicios durante todos

15 «La forma en que el film retrata a Felipe el Hermoso no es muy distinta de la imagen caricaturesca que el propio Franco tenía de don Juan de Borbón, así como la representación del joven Carlos nos remite a las esperanzas que el régimen franquista depositó en Juan Carlos, hijo del "legítimo" heredero a la Corona» (Juan-Navarro, 2005: 207). 
esos años. De hecho, el duelo final de don Álvar y De Vere, en el que Aldara ayuda al castellano matando por la espalda al flamenco es una invención del guion que nada tiene que ver con Tamayo y Baus, pero que concuerda perfectamente con ese «juicio de Dios» al que apela Álvar, y que hace justicia a un personaje tan despreciable y causante de tantos males.

\section{EN CLAVE DE COMEDIA}

El siguiente retrato de cierta profundidad de Juana I de Castilla en el Cine es Juana la Loca... de vez en cuando (1983). Su director, José Ramón Larraz, nombre destacado del cine del destape y del género de terror en España, se sumaba con esta película a otra curiosa moda de los inicios de la década de 1980, una serie de sátiras históricas de limitado gusto artístico y contenido irreverente, planteadas como anacrónicas recreaciones del pasado en clave de total presente. Conocidos son títulos como El Cid Cabreador (1983) o La loca historia de los tres mosqueteros (1983), ambas con guion de Juan José Alonso Millán, que también firmaba esta visión satírica de la figura de Juana. Con un reparto encabezado por Lola Flores como Isabel de Castilla y José Luis López Vázquez como Fernando de Aragón, el papel de Juana correspondía a Beatriz Elorrieta, quien, por cierto, ya la había encarnado de manera fugaz en la anterior Cristóbal Colón, de oficio... descubridor (1982), también escrita por Alonso Millán.

Juana la Loca... de vez en cuando estaba planteada con una perspectiva de presente y se encontraba «repleta de alusiones a la situación social y política que vivía España en los años ochenta» (Payán, 2007: 76), aunque es cierto que arrastra como enorme lastre que «lo único que tiene de histórico son los nombres de los personajes» (Rubio, 2007: 39). En cuanto a la Juana reflejada en esta parodia, se trata de una mujer moderna (de la década de 1980, no de los siglos XV-XVI), liberada y asaltada por continuos deseos sexuales, que solo podrá refrenar cuando se enamore del cantante y mujeriego Felipe de Flandes, interpretado en la película por el cantante Jaime Morey. Más allá del capítulo cómico o de sus muchas limitaciones, no cabe duda de que su argumento no tiene ninguna intención de adaptar el drama de Tamayo y Baus, y solo puede rastrearse algún eco puntual y muy libre de la película de Orduña.

\section{El REMAKE COMPUESTO}

En 2001 se estrenaba Juana la Loca, otra de las adaptaciones del drama de Tamayo y Baus que, si bien no es la más cercana al mismo, sí es la que hace más justicia a la figura de Juana, aunque no tanto en su condición de reina, sino sobre todo de mujer. Inserta ya en el cine español del nuevo 
milenio, las perspectivas han cambiado mucho respecto a las anteriores producciones analizadas, y son mayores los intereses en aspectos psicológicos y sociológicos:

Juana la loca responde, además, a una vertiente histórica completamente distinta a la del cine español de la autarquía (1939-1953), las corrientes historiográficas se han alejado del positivismo, y avanzan hacia un mayor nivel de contextualización, de análisis de la sociedad en su conjunto (López López, 2004: 125).

Coproducida entre España, Italia, Portugal y Francia, Vicente Aranda se encargó de la dirección y el guion, añadiendo así este título a otras de sus adaptaciones de conocidas obras literarias contemporáneas, como La muchacha de las bragas de oro (1980), El amante bilingüe (1993) o La pasión turca (1994), una senda que continuaría posteriormente con Carmen (2003) o Canciones de amor en Lolita's Club (2007). Aranda volvía a ponerse al frente de una recreación cinematográfica del pasado, como ya hiciera en Libertarias (1996) o años después con su adaptación de la novela medieval Tirante el Blanco (2006). Además, Juana la Loca era otra de las varias ocasiones en las que ha centrado sus películas en personajes femeninos, adentrándose de hecho en una perspectiva de género que ha sido aplaudida por crítica y espectadores. Del mismo modo, esta película también se relaciona con la «temática del amour fou, tan presente en la filmografía de Aranda, Amantes (1991), La pasión turca (1994) o Celos (1999), por poner algunos ejemplos» (López López, 2004: 125).

Juana la Loca se planteó como una ambiciosa producción de género histórico y son realmente destacables su esmerada puesta en escena y su ambientación, que pretenden aportar fidelidad al conocimiento histórico y artístico de la época retratada. En el reparto hay mayoría de intérpretes españoles, con nombres conocidos como Eloy Azorín (Álvaro de Estúñiga), Rosana Pastor (Elvira), Roberto Álvarez (almirante de Castilla), Susi Sánchez (Isabel I de Castilla) o Guillermo Toledo (capitán Corrales). Junto a ellos, varios intérpretes provenientes de Italia en algunos papeles importantes, como Daniele Liotti (Felipe I de Castilla), Giuliano Gemma (Señor de Veyre) o Manuela Arcuri (Aixa). Y para el papel de Juana, la joven intérprete española Pilar López de Ayala, quien ya había tenido pequeños papeles en el Cine con anterioridad, así como un protagonista en Báilame el agua (Josetxo San Mateo, 2000), pero que con Juana la Loca realizaba su primera interpretación protagónica en una producción de gran calibre. Por cierto, su interpretación la realizó con casi la misma edad que la de Aurora Bautista en 1948, ya que López de Ayala llegó al estreno de la película el 28 de septiembre de 2001 con 23 años recién cumplidos. La cinta tuvo una gran acogida de público, 
llegando a recaudar casi el doble de sus cerca de cinco millones de euros de presupuesto. Además, fue la cinta seleccionada para representar a España en la candidatura a la Mejor Película de Habla no Inglesa en la ceremonia de los Oscar de 2002, a lo que hay que sumar como reconocimiento numerosos premios en varios certámenes ${ }^{16}$.

En los propios títulos de crédito de Juana la Loca se menciona que «Algunas escenas de esta película están basadas, aunque muy libremente, en la obra de teatro de Manuel Tamayo y Baus titulada La Locura de Amor», y no cabe duda de que el guion del propio Vicente Aranda así lo atestigua en algunas situaciones y algunos diálogos. Pero esta producción de 2001 puede ser considerada como un remake compuesto, ya que toma «elementos tanto del texto literario como de la película matriz» (Malpartida Tirado, 2012: 370). En efecto, la cinta de Aranda apela al drama teatral de Tamayo y Baus, pero también a la matriz cinematográfica de las adaptaciones del mismo, la película de Orduña de 1948, de la cual recoge algunas escenas, pero siempre desde una perspectiva más naturalista, menos teatral en su acción y en sus diálogos.

La narración se enriquece y diversifica respecto al drama de Tamayo y Baus en cuestiones como la cronología, siendo esta la película que recorre más años en la longeva vida de Juana. La acción se inicia en el presente de su retiro en Tordesillas hacia 1554, con una Juana anciana que se dispone a rememorar su vida cuando fija su atención en un «retrato de Felipe el Hermoso, su difunto marido» (Santana y Santana, 2007: 88). La acción vuelve entonces a 1496 para situar, apoyándose en una voz fuera de plano, a la propia Juana justo antes de embarcar en Laredo para trasladarse a Flandes y casarse con el archiduque Felipe de Habsburgo. A partir de ahí la acción continúa con un prolongado flashback en la corte de Flandes, para después narrar los hechos acaecidos en Castilla desde la llegada del matrimonio en 1506 hasta la muerte de Felipe. Y de nuevo la película se cierra en el presente de 1554, después de que Juana haya rememorado las razones de su reclusión en Tordesillas.

${ }^{16}$ Goya a la Mejor interpretación femenina protagonista (Pilar López de Ayala), al Mejor diseño de vestuario (Javier Artiñano) y al Mejor maquillaje y/o peluquería (Miguel Sesé y Mercedes Guillot); Concha de Plata a la mejor actriz en el Festival Internacional de Cine de San Sebastián (Pilar López de Ayala); Premio del Círculo de Escritores Cinematográficos a la mejor actriz (Pilar López de Ayala); Fotogramas de Plata a la mejor actriz de cine (Pilar López de Ayala); Premios de la Unión de Actores a la actriz revelación y protagonista de cine (Pilar López de Ayala); Premio de la Asamblea de Directores y Realizadores Cinematográficos Españoles (ADIRCAE) a la Mejor interpretación protagonista (Pilar López de Ayala). 
La trama central de Juana la Loca se aleja del círculo amoroso planteado en el drama teatral para intentar abordar una perspectiva algo más cercana a la propia Historia y a los datos manejados sobre Juana más allá de su supuesta locura. De este modo, las relaciones amorosas se reflejan mediante una disposición lineal, en la que Juana ama de forma arrebatada a Felipe, mientras este se demuestra adúltero en Flandes y se prenda en Castilla de la exótica y enigmática Aixa, el personaje que en esta ocasión no solo adopta un nuevo nombre distinto a la Aldara de Tamayo y Baus, sino que pierde la consideración de princesa descendiente de los reyes nazaríes para revelarse como una prostituta que arriesga su vida por su origen morisco y es una protegida del personaje secundario del capitán Corrales. El personaje de don Álvar, tan determinante en la obra de Tamayo y Baus, atiende ahora al nombre de Álvaro de Estúñiga y es una mera comparsa que solo intervendrá de forma puntual en la acción principal cuando Juana le utiliza para intentar dar celos a su marido. En cuanto al resto de personajes secundarios, merece la pena mencionar la aparición en el contexto de 1496 de Isabel I de Castilla, intentando explicar a Juana los motivos y la necesidad de su matrimonio de conveniencia. Su dama de compañía doña Elvira o el médico Marliano aparecen también con un peso mucho menor, algo que también ocurre con el almirante de Castilla o con los nobles afines a Felipe, tanto el señor de Veyre como don Juan Manuel y el marqués de Villena. En cuanto al nudo argumental, los más que fundados celos de Juana no necesitan de las asechanzas del antagonista creado en la cinta de Orduña, por lo que De Veyre queda en esta ocasión como un mero apoyo de Felipe con mucha menor interferencia en relación de la pareja regia. El carácter del monarca flamenco es de sobra conocido por la corte castellana («El rey es un mujeriego impenitente, indigno del amor que le dedica la Reina», declara el almirante de Castilla), y ahí radica una de las grandes diferencias de esta película con la de 1948, en la certeza desde el principio de los continuos desprecios de Felipe hacia su devota esposa. De hecho, a pesar de que hay ciertas insinuaciones sobre arrebatos o conductas impropias de una reina, Juana no se despoja en ningún momento de su dignidad como mujer, y sus celos no devienen en momentos de enajenación, sino de rabia exagerada por parte de una mujer que ama de forma desenfrenada sin verse correspondida. La irrupción de Aixa en la Corte como la dama Beatriz de Bobadilla, asistida por don Juan Manuel y el marqués de Villena como respuesta a la petición expresa del rey para satisfacer su capricho carnal, no hará más que empeorar la situación precedente. Los hechos finales incluyen una perspectiva histórico-política al mostrar la entrevista entre Felipe y Fernando de Aragón, que no hace más que refrendar el desprecio de ambos hacia Juana. La referencia expresa de Fernando a la locura de Juana («Ahórrate las excusas, mi hija 
Juana está loca») es una de las pocas ocasiones en las que alguien habla abiertamente de ello, siempre de forma interesada, como ocurre en un par de ocasiones en las que De Veyre apela, como ya hiciera el personaje en la película de 1948, a la locura de su abuela Isabel de Portugal, pero añadiendo en esta ocasión el fanatismo y obcecación de su propia madre, Isabel I de Castilla. A pesar de la reacción de dignidad de Juana frente a las Cortes en Burgos, su extravagancia termina por sellar su incapacidad para gobernar, aunque la repentina muerte de Felipe deja de nuevo en un segundo plano el tema político para hacer aflorar el arrepentimiento del rey respecto a su esposa, aunque mucho más natural y alejado de la escena creada por Tamayo y Baus.

El excelente papel de Pilar López de Ayala como Juana es uno de los grandes alicientes de la película, y no es de extrañar que recibiera tantos premios por su interpretación, incluyendo el Goya a la Mejor Actriz Protagonista. La joven e inexperta princesa que embarca en Laredo se muestra impotente ante el matrimonio orquestado por su madre por motivos políticos, por mucho que Isabel apele a la providencia divina, aunque la joven finalmente acata la decisión («Os obedezco, madre; sé que mi vida, como la vuestra, está sujeta a mayor empeño que el que corresponde a mi humilde persona»). Lo que en la película de Orduña era tremenda dignidad, incluso en las escenas más desenfadadas, se convierte en la de Aranda en un canto a la juventud de Juana, a la naturalidad y vitalidad de la corte de Flandes, a su vida familiar y maternal, y todo ello con una clara influencia de la pintura flamenca en la esmerada puesta en escena.

López de Ayala se aparta del histrionismo teatral de Aurora Bautista y resulta mucho más natural y mucho menos exagerada. Además, en 2001 están más que superados los condicionantes morales o ideológicos que constriñeron al personaje en 1948, por lo que López de Ayala puede dar rienda suelta a una interpretación volcánica que no hace más que obviar la enajenación mental por amor para abrazar de forma decidida una rabia que explota en más de una ocasión en diálogos o ademanes apasionados y muy poderosos. Las intrigas palaciegas para apartarla del poder tienen esta vez motivaciones menos románticas que en las obras de Tamayo o de Orduña, añadiendo verosimilitud histórica a las diferentes maniobras políticas, combinadas con la certeza del comportamiento adúltero de Felipe.

Por otra parte, la imagen de Juana ya anciana en su retiro de Tordesillas, que marca el inicio y el final de la cinta, no es la de una mujer loca con la mirada perdida o unos gestos y ademanes erráticos, tal como Aurora Bautista aparecía en 1948 durante su entrevista con el rey Carlos 
I. Muy al contrario, la Juana de 1554, interpretada por la veterana María Jesús Valdés, desprende serenidad y nostalgia:

Juana aparece olvidada y traicionada por todos aquéllos con los que tenía algún lazo afectivo. La clausura de la reina no parece ser sólo material sino también personal, no figura ninguna escena en su vejez en la que esta entable algún diálogo con otra persona y, en cualquier caso, no se atisba ningún rasgo de locura, sino de una serena tranquilidad (Santana y Santana, 2008: 88).

Al final de la película una voz fuera de plano ayuda a comprender el calvario que Juana debió sufrir después de la muerte de su amado esposo. Pero las últimas palabras de Juana son otra muestra más de la pasión obsesiva que muestra en los flashbacks entre 1496 y 1506, ya que el propio recuerdo de su marido la devuelve al pasado y a volver a sentir los deseos carnales que sentía por él («Tal vez podré olvidar tu nombre, pero jamás el abrazo que me hacía gemir»). Esta culminación del metraje es un ejemplo claro de que la Juana de Aranda «es consciente en todo momento de lo que está sucediendo y sus palabras al final de su vida no traslucen delirio como sucede, contrariamente, en el film de Orduña» (Guillamón Carrasco, 2015: 126).

Si en el texto de Tamayo y Baus o en la película de Orduña el personaje de Juana actúa sobre todo como una reina (un extremo exagerado en la cinta de 1948), este retrato del nuevo milenio se centra principalmente en una perspectiva de género. Juana es ante todo una mujer, y para Aranda «no estaba loca pero se la trató como tal por no resignarse a las infidelidades de su marido, ni adherirse a las tácitas normas de pasividad sexual femenina vigentes en la época» (Gómez, 2006). Ella ama a su esposo y tiene una profunda atracción sexual hacia él desde el mismo instante en el que se conocen. Ella es la madre de sus hijos, a quienes también quiere amamantar como cualquier otra mujer, un hecho que no es baladí, puesto que no había ni rastro de su descendencia en la obra de Tamayo y Baus ni en la película de Orduña. Y hay que tener en cuenta que, como ya se ha referido, tuvieron juntos seis hijos, por lo que Aranda plasma un acto de feminidad tan evidente como la maternidad, ya sea mostrando algunos partos o la lactancia, una actitud que precisamente marca el inicio de las murmuraciones de Felipe hacia su conducta, que considera poco propia para una reina, aunque para ella sea simplemente una muestra lógica de su propia feminidad.

Hablar de remake compuesto a partir del drama de Tamayo y Baus y de la película de Juan de Orduña no significa necesariamente el calco de ninguna de las dos fuentes por parte de Aranda, sino precisamente tomarlas como base para diversas escenas y diálogos. Pero sí hay algunos 
pasajes con relación muy directa, como la escena en la que Juana se dirige a las Cortes de Castilla que han sancionado su incapacidad. Las diferencias de contexto son evidentes, porque la reina aparece visiblemente embarazada de Catalina, hija póstuma de Felipe, pero también porque no hay necesidad de incluir el tejemaneje de la carta de la morisca para probar la infidelidad del rey. Juana acude a las Cortes después de que el almirante de Castilla y Álvaro de Estúñiga soliciten su presencia por cuestiones de estado, para que el trono no sea entregado a la codicia de los flamencos. De ahí la gran dignidad que Juana muestra en las Cortes, en las que desprecia de forma poderosa a los secuaces de Felipe y al propio rey, para abandonar la escena bromeando sobre la supuesta locura que le achacan («Señores, quedad con Dios. La reina loca os saluda»).

\section{El último retrato, entre la Televisión y el Cine (Sin atisbo de ADAPTACIÓN)}

La última ocasión hasta la fecha actual en la que Juana I de Castilla aparece en la gran pantalla es La corona partida (2016), una película estrenada en cines, pero surgida a partir de las series televisivas Isabel (2012-2014) y Carlos, rey emperador (2015-2016), y cuya acción se sitúa precisamente entre ambas, siendo secuela de la primera y precuela de la segunda. Como corresponde a su origen televisivo, la mayoría del equipo procede de la pequeña pantalla y más concretamente de las dos series mencionadas. Por ejemplo, el director barcelonés Jordi Frades ya atesoraba una sólida experiencia en películas y series televisivas, incluyendo ponerse al frente de 14 episodios de Isabel. Caso parecido es el del guionista, José Luis Martín, también con probada experiencia televisiva y con escritura de la mayoría de capítulos tanto de Isabel como de Carlos, Rey Emperador. Y, por supuesto, por razones de argumento, el reparto de La corona partida mantiene muchos de los personajes e intérpretes de Isabel, pudiendo ser destacados nombres conocidos de la televisión y el cine españoles como Rodolfo Sancho (Fernando II de Aragón), Eusebio Poncela (cardenal Cisneros), José Coronado (Maximiliano I de Habsburgo), Fernando Guillén Cuervo (Gutierre Gómez de Fuensalida), Úrsula Corberó (Margarita de Austria) o Michelle Jenner en su fugaz (y fantasmal) aparición como Isabel I de Castilla. Para los papeles principales de Juana y Felipe se mantenían también los jóvenes Irene Escolar y Raúl Mérida. Al igual que sucede en las series, esta película tiene una puesta en escena realmente cuidada, con algunas localizaciones reales que añaden verosimilitud al pasado recreado. Pero su condición de producto derivado de producciones televisivas restó lógicamente cantidad de público en salas cinematográficas, teniendo en cuenta que sería mucho más aconsejable su visionado tras haber visto, al 
menos, una serie larga en capítulos como Isabel. Además, el hecho de que el estreno tuviera lugar el 19 de febrero de 2016, poco después de que la serie Carlos, rey emperador ya hubiera finalizado sus emisiones televisivas, se antoja otro escollo difícil de superar, una vez que ambas series ya habían cerrado sus emisiones.

En cuanto al argumento, la frase publicitaria de su cartel sirve como perfecto resumen: «Tras la muerte de Isabel todos quieren demostrar que Juana, la legítima heredera, está loca». En efecto, la trama se centra en los movimientos políticos para apartarla del poder, aunque el argumento ya no tiene ninguna relación con el drama de Tamayo y Baus, sino que se apoya sobre todo en su serie matriz Isabel y en una base histórica que, en realidad, la hace mucho menos llevadera por comportar una sucesión demasiado abigarrada de hechos, fechas y personajes en un metraje insuficiente que parece pedir a gritos el desarrollo en varios capítulos de otra hipotética serie. En cuestiones cronológicas, la estructura es bastante similar a la de la película de Orduña, puesto que la narración comienza su ambientación en Madrigalejo, en enero de 1516, en el lecho de muerte de Fernando de Aragón; allí, el cardenal Cisneros relata al aún príncipe Carlos los hechos relativos a la subida al poder de sus padres, tal como don Álvar hiciera en la película de 1948, pero sin que aparezca en ese momento la propia Juana anciana. Se plantea entonces un amplio flashback que abarca desde después de la muerte de Isabel I de Castilla en 1504 hasta aproximadamente 1507, comenzando en tierras de Flandes y terminando ya con la estancia de Juana y Felipe en Castilla. Al final del metraje la acción vuelve a Madrigalejo y al relato de Cisneros, que se va combinando con una serie de textos en la pantalla para contextualizar los últimos años de Juana, así como la muerte de Fernando y la aparición fantasmal de Isabel en su lecho de muerte, una maniobra que de nuevo se antoja demasiado deudora de la serie Isabel y que aporta muy poco a $L a$ corona partida.

La definitiva separación del guion de La corona partida respecto a $\mathrm{La}$ locura de amor elimina por completo cualquier atisbo de estructura circular para dar lugar a una relación de confrontación sin cuartel entre Juana y Felipe. De hecho, a pesar de que Juana sea el personaje central de la película, su condición de instrumento para los designios políticos de los demás (en especial su padre y su esposo) resta importancia a sus actos. Además, la profusión de personajes con cierta relevancia en la narración excede con mucho los de la obra teatral o las películas anteriores, y todos ellos intervienen de algún modo en el destino de Juana, tanto en lo personal como en lo político. Desde 1504, cuando en la corte de Flandes se conoce la muerte de Isabel I y que Juana es la legítima heredera del trono de Castilla se desarrolla un verdadero infierno para ella, que vive separada y totalmente enemistada con Felipe, con un marcado desprecio 
entre los esposos. Su inminente subida al trono castellano genera diversas intrigas por parte de Felipe para apartarla del poder aprovechando la declaración de su incapacidad. Pero, al mismo tiempo, Fernando de Aragón y el cardenal Cisneros conspiran en Castilla con la misma excusa para seguir las instrucciones del testamento de Isabel, según el cual Fernando sería el encargado de la regencia de Castilla si Juana no estaba en condiciones de gobernar, hasta la mayoría de edad de Carlos de Austria, el hijo de Juana y Felipe, y heredero de ambas coronas.

Llegado el momento, con Juana y Felipe ya en Castilla, Fernando debe dar un paso atrás y volver a Aragón a cambio de un sustancioso acuerdo económico, mientras se casa con Germana de Foix con la intención de engendrar un heredero y asegurar el futuro de la corona de Aragón ante la tensa situación y las pretensiones de Felipe. La corona que habían unido por matrimonio los Reyes Católicos está a punto de partirse de nuevo en dos, y en medio de todos estos movimientos se encuentra una Juana repudiada por todos, vilipendiada por su marido y utilizada como moneda de cambio política sin tener en cuenta su propia opinión. La repentina y sospechosa muerte de Felipe da un nuevo giro a los acontecimientos, con Juana sumida en la melancolía y renunciando finalmente a ejercer el poder, que queda en manos del cardenal Cisneros con el beneplácito de Fernando. La narración vuelve entonces al momento de la muerte en 1516 del rey aragonés, quien no pudo tener descendencia, por lo que el joven Carlos al que Cisneros relata todos estos hechos hereda finalmente las coronas de sus abuelos maternos, los dominios de su propio padre y el imperio de su abuelo paterno.

La encargada de encarnar a Juana en esta película fue la joven Irene Escolar, quien ya tenía a sus espaldas por entonces cierta experiencia en Cine y Televisión, incluso con algún papel protagonista. Su papel en esta cinta, al igual que previamente en la serie Isabel, llega a resultar excesivo, acercándose al histerismo. No cabe duda de que esta exageración responde a las exigencias de un guion en el que no existe ningún trastorno mental o comportamiento exagerado o enajenado, sino rabia desatada por el infierno personal al que se enfrenta. A pesar de que el testamento de su madre o una declaración de su marido ratifiquen su incapacidad y su falta de libre albedrío, Juana es simplemente una persona acorralada por los acontecimientos políticos. Es despreciada por cuantos la rodean porque les interesa muy poco la persona, pero mucho el poder que recibe por herencia, y que todos desean para sí mismos. Su marido llegará a encerrarla en un calabozo de su palacio en Flandes o la llamará «perra», y también se encontrará en mitad de un fuego cruzado entre Felipe y Fernando, junto a sus respectivos partidarios, que no dudan en generar todo tipo de intrigas alrededor de su supuesta incapacidad, sin que en 
ningún momento aparezca ningún indicio fundado de ello. Ya en Castilla, Juana aparece indefensa y excluida de las reuniones de estado entre su marido y su padre, que la utilizan como objeto para sus ansias de poder. Uno de los ejemplos más claros de la rabia de la reina ante los acontecimientos que la rodean es la escena en la que es informada de que no podrá llegar a ver a su padre en Castilla, después de haberse entrevistado con Felipe. Su dignidad aparta cualquier indicio de locura, demostrando que es una persona a la que no le permiten hacer nada, a pesar de ser toda una reina de Castilla. También se mostrará ante los nobles como una mujer digna, pero presionada hasta el extremo por las circunstancias. No podemos hablar de una perspectiva de género tan marcada como en la película de Aranda por esa ausencia de pasión o celos, pero al menos la Juana de la cinta de Frades se muestra como una mujer que lucha con entereza contra los acontecimientos, e incluso al final del metraje una escena recoge el nacimiento de Catalina, la hija póstuma de Felipe. Por cierto, en esta película de ambientación tan cuidada no podía faltar la referencia visual al cuadro de Pradilla que ya se había recreado en ocasiones anteriores.

\section{CONSIDERACIONES FINALES, A MODO DE RECAPITULACIÓN}

Las relaciones entre Historia, Literatura y Cine pueden ser analizadas a partir de las películas que retratan a Juana I de Castilla, en las cuales puede rastrearse la relación directa o indirecta y en mayor o menor medida con el drama teatral La locura de amor de Manuel Tamayo y Baus. La primera, dirigida por Marro y Baños en 1909, se basa en la obra teatral, pero también recibe otros apoyos histórico-biográficos. La de Orduña de 1948 es sin duda la más próxima adaptación, aunque también se ve apoyada de una forma muy interesada por el conocimiento histórico para entroncar con la consideración de película "de interés nacional". La de Larraz de 1983 no tiene ninguna relación con el drama, porque no lo necesita para un guion centrado en lo cómico y lo anacrónico, que, en cualquier caso, se fija en la película de Orduña para algunos detalles menores. La de Aranda en 2001 es un excelente ejemplo de remake compuesto, ya que no solo adapta La locura de amor, sino que también toma muchos elementos de la película de 1948, aunque con una clara puesta al día, en especial del papel de Juana; además, muestra una sólida base histórica y una acción de cronología mucho más amplia que la teatral. Por último, la de Frades no tiene relación directa con la obra de Tamayo, pero sí intenta crear un retrato histórico que, en todo caso, se excede por abigarrado; en ella solo podría hablarse de algunos detalles muy concretos que evocan de forma bastante libre algunas ideas planteadas en las películas de Orduña o Aranda. 
Un personaje tan enigmático y fascinante como Juana I de Castilla, la Loca, tiene un gran potencial para interesar a un medio tan importante como el Cine. Así, el Séptimo Arte ha recurrido a su infausta y legendaria vida no solo para llamar la atención del público y obtener los deseados beneficios, sino también como instrumento ideológico para justificar el presente al revisar la trascendental época en que vivió. Dejando aparte su escueto retrato en 1909 hay que detenerse en la Juana encarnada por Aurora Bautista en 1948, que responde a unos claros condicionantes ideológicos en consonancia con el primer franquismo o período de la autarquía, dentro de la estrategia de utilizar el cine histórico como instrumento propagandístico de primer orden para reafirmar la ideología nacional-catolicista. Al igual que otras películas de género histórico del momento que recreaban épocas decisivas de la Historia de España como referentes pasados para justificar el régimen franquista, Locura de amor apela a la conformación de España como Estado-nación y al nacimiento del espíritu nacionalista español. Ejemplo de ello es hacer corresponder a Juana y a sus desgracias con Castilla y, por afinidad, con España, equiparando así el sufrimiento de Juana al maltrato que el pueblo castellano comenzaba a sufrir de los flamencos y la nobleza afín a Felipe; es lo que Juan-Navarro define como «la Patria enajenada como resultado de las maquinaciones de las potencias extranjeras» (2005: 207). La dignidad de España y su superioridad frente al enemigo (tanto externo como interno) disculpan la locura de Juana por los celos, que en todo caso responden también desde una perspectiva xenófoba a las intrigas de Felipe y su consejero flamenco Filiberto de Vere.

Dejando aparte la ligereza anacrónica de la comedia de 1983, hay que centrarse también en la película de 2001, una cinta con una carga política muy inferior a la de 1948, realizada en un contexto sin claras imposiciones ideológicas, sin censura estatal y sin necesidad de alegorías nacionalistas. Vicente Aranda dignifica a Juana, mostrándola como un personaje atormentado y pasional del que extrae una historia intimista e individualizada, pero sin tanto hincapié en su componente histórico y tomándolo como un estereotipo social. Los intereses políticos que la rodearon son parte de la ambientación de la época, pero no hechos determinantes en el desarrollo del relato. Aranda dota a Juana de inocencia ante el matrimonio y de curiosidad sobre el sexo, a veces de forma algo exagerada, aunque entroncando con su interés en la figura femenina en su filmografía. La actitud noble e inocente de Juana, unida a la traición y humillación que sufre a causa de sus fundados celos, la despojan de la gran carga trágica presente en las obras de Tamayo y de Orduña para hacer de ella un ejemplo de mujer íntegra e injustamente vapuleada por su entorno. Juana la Loca se convierte por tanto en un 
verdadero alegato a favor del género femenino $\mathrm{y}$, de forma indirecta, en una denuncia hacia el patriarcado o la terrible lacra de la violencia de género.

Por su parte, la película de 2016 quería mostrar las pasiones de unos esposos ilustres o las intrigas palaciegas de importantes cortes europeas, pero seguramente había muchas otras maneras de hacerlo en lo referente a los diálogos, tan explosivos y directos como excesivamente actuales en sus formas y en parte de su fondo. No cabe duda de que esta película estaría condicionada por un público potencial acostumbrado a contenidos televisivos variados, pero en muchas ocasiones las soluciones son muy poco creíbles, además del mencionado problema de comprimir en algo menos de dos horas un argumento tan intrincado que habría necesitado de varias horas para tener un ritmo coherente y llevadero, lo cual solo podría corresponder a una serie en varios capítulos.

Como consideración final, hay que volver a reconocer el valor del Cine como documento histórico no solo del posible pasado que pueda recrear, sino también del presente en el que se desarrolla. Las películas son un signo de los tiempos, un reflejo de la sociedad de la que emanan, y estas representaciones cinematográficas de Juana I de Castilla son una buena prueba de ello. Si queremos pensar en cómo han cambiado los tiempos, a pesar de salirnos de la gran pantalla y visitar por un momento a su hermana pequeña, la serie Isabel, de la que proviene La corona partida, puede servir de ejemplo para llevar al extremo estos tremendos cambios en la representación de Juana. En la tercera temporada de la serie, en su capítulo 37, titulado «La llamaban Juana la loca» (2014), existen dos escenas situadas cronológicamente durante la estancia de Juana en Castilla impuesta por sus padres tras haber sido jurada heredera por las Cortes de Castilla en 1502 y tras haber abandonado Felipe tierras castellanas. Semejante episodio de tensión entre Juana y sus padres, a pesar de haber sido recogido en la historiografía, no había sido tratado hasta entonces en las producciones cinematográficas sobre ella. Incluso puede deducirse que se trata de una situación bastante difícil de abordar por su iconoclastia respecto a la supuesta infalibilidad y grandeza de Isabel (y, por extensión, de Fernando). Pero el hecho de que la Juana encarnada por Irene Escolar pueda permitirse el lujo en estas escenas de insultar en su cara a todos unos Reyes Católicos es un signo de los tiempos. Porque la sociedad cambia sus gustos y modifica sus límites, al igual que hacen la Literatura, el Cine y los demás medios audiovisuales.

\section{BibliografíA CITADA}

ANónimo (2003), Historia de la célebre reina de España Doña Juana, llamada vulgarmente la Loca [ed. digital basada en la de Madrid, Imprenta de D. José María Marés, 1848], Alicante, Biblioteca Virtual Miguel de 
Cervantes

[En

línea:

http://www.cervantesvirtual.com/nd/ark:/59851/bmc5h7c6].

BENET, Vicente J. (2012), El cine español. Una historia cultural, Barcelona, Paidós.

Bernal, Antonio-Miguel (2007), Historia de España. 3. Monarquía e imperio, Barcelona, Crítica-Marcial Pons.

CAPARrós Lera, José María (2007), Historia del cine español, Madrid, T \& B.

Dávila Vargas-Machuca, Miguel (2007), «Locura de amor o pasión obsesiva: la figura de Juana la Loca en el cine», Metakinema. Revista de Cine e Historia, 0, págs. 113-130.

EsPaÑA, Rafael de (2013), «La Antigüedad al servicio de la actualidad. Cómo las ideas del presente influyen en la recreación cinematográfica del pasado», en B. Antela-Bernárdez y C. Sierra Martín (eds.), La Historia Antigua a través del Cine. Arqueología, Historia Antigua y tradición Clásica, Barcelona, Universitat Oberta de Catalunya, págs. 45-76.

GaSCA, Luis (1998), Un siglo de cine español, Barcelona, Planeta.

GómEZ, María Asunción (2006), «Mujer, nación y deseo en Locura de amor de Juan de Orduña y Juana la Loca de Vicente Aranda», FilmHistoria, XVI/1-2 [En línea: http://www.publicacions.ub.edu/bibliotecaDigital/cinema/filmhist oria/2006/REVISTAS/Ensayo MujerNacionDeseo\%20 1.htm].

GUILlamón CARRASCO, Silvia (2015), «La sexualización de la heroína histórica en el cine español: de Locura de amor a Juana la Loca», Asparkía, 27, págs. 113-130.

JuAN-NAVARRO, Santiago (2005), «La madre patria enajenada: Locura de amor, de Juan de Orduña, como alegoría nacional», Hispania, 88, págs. 204-215.

Juan-Navarro, Santiago (2008), «Political madness: Juan de Orduña's Locura de amor as a National Allegory», en M. A. Gómez, S. JuanNavarro, P. Zatlin (eds.), Juana of Castile. History and Myth of the Mad Queen, Lewisburg, Bucknell University Press, págs. 210-221.

LÓPEZ LÓPEZ, Yolanda (2004), «Visiones sobre Juana la Loca: las recreaciones de Juan de Orduña y Vicente Aranda», en J. Cabeza y A. Rodríguez (coords.), Creando cine, creando historia: la representación cinematográfica de ideas y movimientos sociales, Madrid, Universidad Complutense, págs. 117-130.

Malpartida Tirado, Rafael (2012), «Dos obras maestras de la adaptación de la novela al cine: El último refugio y Retorno al pasado», en J. Sánchez Zapatero y A. Martín Escribá (coords.), El género negro: el fin de la frontera, Santiago de Compostela, Andavira, págs. 367-375. 
Malpartida Tirado, Rafael (2018), «La recepción y el canon de la literatura y el cine: sugestiones y replanteamientos», en $\mathrm{R}$. Malpartida Tirado (coord.), Recepción y canon de la literatura española en el cine, Madrid, Síntesis, págs. 17-53.

Mínguez Martín, Luis (2004), «Psicobiografía de Doña Juana I de Castilla y Aragón», Informaciones Psiquiátricas, 175 [En línea: http://www.informacionespsiquiatricas.com/anteriores/info 2004 /01 175 05.htm]

MONTERDE, José Enrique (2000), «El cine de la autarquía (1939-1950)», en R. Gubern et al., Historia del cine español, Madrid, Cátedra, págs. 181-238.

PayÁn, Miguel (2007), La historia de España a través del cine, Madrid, Cacitel.

Pérez Perucha, Julio (2000), «Narración de un aciago destino (18961930)», en R. Gubern et al., Historia del cine español, Madrid, Cátedra, págs. 19-121.

Pfandl, Ludwig (1969), Juana la Loca. Su vida, su tiempo, su culpa, Madrid, Espasa-Calpe.

Rubio, Ramón (2007), La historia de España a través del cine, Madrid, Polifemo.

Rubio JimÉnEZ, Jesús (2004), «Un drama nuevo, de Manuel Tamayo y Baus: las paradojas del comediante y del juego dramático», Arbor, 699-700, págs. [En 677-690 línea: https://doi.org/10.3989/arbor.2004.i699/700.603].

SÁNCHEZ-BiosCA, Vicente (2012), «Una nación de cartón-piedra. Las ficciones históricas de Cifesa», en I. Saz y F. Archilés i Cardona (coords.), La nación de los españoles: discursos y prácticas del nacionalismo español en la época contemporánea, Valencia, Universitat de València, págs. 499-519.

Santana Pérez, Juan Manuel y Germán Santana Pérez (2008), Las representaciones de la Historia Moderna en el cine, Las Palmas de Gran Canaria, Anroart.

Seguin, Jean-Claude (1997), «Locura de amor», en J. Pérez Perucha (ed.), Antología crítica del cine español. 1906-1995, Madrid, Cátedra, págs. 230-232.

TAmayo y Baus, Manuel (2000), La locura de amor [ed. digital a partir de Obras Completas, Madrid, Fax, 1947], Alicante, Biblioteca Virtual Miguel de Cervantes [En línea: http://www.cervantesvirtual.com/nd/ark:/59851/bmcw9549].

Torreiro, Casimiro (1999), «Por el imperio hacia Dios. El cine histórico de la autarquía», en J. E. Monterde (coord.), Ficciones históricas. El cine histórico español, Madrid, Academia de las Artes y las Ciencias Cinematográficas, págs. 53-65. 
Miguel Dávila Vargas-Machuca

Tusell, Javier (1999), Historia de España en el siglo XX. III. La dictadura de Franco, Madrid, Santillana.

Fecha de recepción: 30/05/2019.

Fecha de aceptación: 27/06/2019. 